\title{
Image and Textual Design Strategies in Native American Literature
}

\author{
David Erben ${ }^{1}$, Yulia Privalova $^{2,}{ }^{*}$, Alexey Yakovlev $^{2}$, and Victoria Ovcharenko ${ }^{2 .}$ \\ ${ }^{1}$ University of Toledo, Department of English Language and Literature, 2801 W. Bancroft St., Mail Stop 126, Toledo, USA \\ ${ }^{2}$ Southern Federal University, Department of Linguistics, 44 Nekrasovky lane, 347922, Taganrog, Russia
}

\begin{abstract}
The article deals with the creative ways in which a number of Native American authors offer characters and various approaches of readers to discovering "the center", which becomes a rich and diverse experience that can also reveal the writer's deep self-awareness as a storyteller. These centers, which are critical to the development of the character, image, and plot, can also determine the overall structure and concept of the story. Being the result of the self-reflectiveness of the narrators and controlling the whole narrative concept, such centers have precedents in the traditional Native systems of poetics.
\end{abstract}

\section{Introduction}

Many Native American authors offer characters and various approaches of readers to discovering "the center" through circles implied by parallel opening and closing images and by characters' "homing in" movements; through images that evoke the cardinal axes and through key characters who set bearings that orient narrating voices. With such carefully developed guidance, discovering "the center" becomes a rich and varied experience that can also reveal the writer's deep selfawareness as storyteller. These centers, critical for character, image, and plot development can also govern overall narrative structure and conception. The role of "the center" as a principle of poetics becomes clearer as we consider, along with Set's father in The Ancient Child, how "the story" itself can be a "space" with a "center".

In addition to characters who orient narrating communities, the center appears in these works as fundamental to design in at least two ways. The first, seen in several instances, results from drawing the individual present at the center of a continuous historical process; the second, articulated by Momaday, privileges a creative silence as the ultimate source for "the story" conceived as circle.

As with the grounding strategies discussed above, these centers, which result from the self-reflexivity of storytellers and can govern an entire narrative design, have precedents in traditional Native systems of poetics.

\section{Materials and methods}

Although the circularity of these texts implies ongoing processes, individual narratives nevertheless begin at specific points. In several works the initial moment is the beginning of History itself. Allen opens her novel at this globally significant moment as the mythic voice parodies the rhetoric of the King James Genesis: "In the beginning was the Spider" (The Woman 1). Allen associates mythic and individual histories throughout the text. She merges these double perspectives in the final chapters, as Ephanie understands her own potential not as a "dead end," but as a dynamic threshold between cultures. The closing vision of Ephanie, singing along with the mythic and realistic ancestral spirits, implies that among the spaces into which this threshold figure offers entry is the narrative "space" that is the history of the world, as construed in the work [1]."

The personal voice of Momaday's Rainy Mountain can also be seen as an individual conceptual and experiential entry into the story making process that unites mythic and documented Kiowa history [2]. Kimberly Blaeser, taking the perspective of a reader-response theorist, sees Momaday in the personal lyrical voice as "enacting the reader role" and as transforming his definition of self in the narrative process. The resulting text, Blaeser argues, "ultimately collapses in the continuum of time in what Joesph Epes Brown has called "the perennial reality of the now" [3].

Momaday's careful stylistic choices are important for uniting "the now" with the continuum of time. Rainy Mountain, like Allen's novel, begins at the beginning of all history, as the Kiowa emerge from the hollow log. The work as a whole, like each segment in it, moves from the "distant" mythic past, through the documented past, into the individual present. Despite distinctive differences in the point of view (third person vs. first person) and tone (authoritative v. lyrical), the mythic and personal voices share significant elements. In addition to shared formulae, temporal categories in both are general in contrast to the documentary voice's specific dates and chronologically sequenced time past. Furthermore, key individual personae, such as Mammedaty and "my grandmother," originate in personal, move into documented and then into

\footnotetext{
*orresponding author: privalovatyu@sfedu.ru
} 
mythic modes. As these common elements conceptually merge the "moments" of history, Momaday's personal and cultural experience, like the Kiowa's kinsmen in the sky, rises to an dimension beyond documented history. Style is thus one signal when the recent personal past provides entry into the total temporal and spatial continuum of the journey encompassed by the texts of the three narrating voices [4].

Additional image and textual design strategies validate the view that the historical continuum entered through these contemporary individual thresholds. The character of Ephanie and the personal voice of Rainy Mountain can appropriately be conceived as circular. In Ephanie's final vision, Allen places "around" her protagonist the shadows and voices of ancestral spirits (the Spider Medicine Society), just as she has metaphorically encircled Ephanie's life story with the mythic history [1]. Momaday also encircles the individual with history [4]. Most of the essays in Kenneth Roemer's collection (Approaches) point out the circularity of Rainy Mountain's images. Helen Jaskoski is particularly helpful in identifying the work's multiple circular elements [5]. As Jaskoski comments, "from earth to sky and back to earth, the Way is circular". Both Momaday's repeated sequencing of mythic, documentary, and personal voices, and his consistent historical focus in prologue, exposition, and epilogue contribute to the sense of the individual as a present center for this circular journey through history.

This reading of the individual present in these particular works as a center for all history coincides with an observation Barre Toelken makes about the implicit circularity of Native American views of the past in general: It is almost as if the individual is surrounded by the past, with the distant past no farther away than the recent (in our terms). Time seems to be viewed, then, as something akin to our sense of space, with the individual in it, rather than with the individual on a ribbon of it [6].

Allen's novel and Momaday's history demonstrate in literary form this sense of the individual within an historical process which is simultaneously distant and recent and which, as image and textual design imply, takes circular form.

This particular literary shaping, in which the narrative beginning coincides with the beginning of all history, and in which the ending emphasizes the individual "now," has parallels in some important traditional histories. The alphabetic transcription of the Quiche Popol Yuh, one of the earliest relatively complete recorded histories of precolonial America, illustrates this structure. The Popol Vuh begins with the creation of the world. A council of creators, employing a phenomenological method like Grandmother Spider's, "conceive the emergence of the earth from the sea. On their fourth attempt the creators produce satisfactory humans, who, like Momaday's Kiowa ancestors in Rainy Mountain and like the Zuni searching for "the Middle place," undertake a journey through the primordial darkness toward the light. As the Quiche lords await the rise of Morning Star and the first dawn, they travel westward from "Tulon Zuyua, Seven Caves, Seven Canyons" [2].

In addition to a journey toward the light that begins along with the cosmos itself, the Popol Vuh shares another important narrative and stylistic element with Rainy Mountain. Through characterization especially, the exposition merges mythic and realistic modes of discourse. In describing the Quiche travels, the storytellers gradually shift from mythic characterization into a "documentary" mode that names actual rulers and lineages. Tedlock comments on the work's later episodes: then in the twelfth generation, the names Three deer and Nine Dog are followed by two sentences whose combination of gravity and brevity gives the reader a chill. The first is, "And they were ruling when Tonatiuh arrived," Tonatiuh or "Sun" being the name given by the Aztecs to Pedro de Alvarado ... And the second sentence about Three deer and Nine Dog is simply, "They were hanged by the Castilian people» [2].

The very last documentation consists of the names of the first Quiche lords who adopted Spanish forms, a documentation, Tedlock argues, dates the alphabetic writing no later than 1558. This Quiche journey through history is like Momaday's in that it begins at the beginning of the world, moves along a continuum through mythic space and time into documented person and place, and concludes in the authors' personal "now."

This historical continuum created through style integrates the distant past and the storyteller's present. In contemporary literature, the present as narrative center for all history is most developed in Momaday's history and in Allen's novel. But other novels hint of such a structuring device as contemporary individual characters act as instruments for completing a local historical process. Silko suggests such an individual center for history in Tayo's experience of the "converging" of all memories at Enchanted Mesa (Ceremony). The completion of family history through the present individual contributes to healing and narrative resolution in both Welch's Winter and Erdrich's Love Medicine [7].

Aside from Allen's, the most pertinent example among the novels is Welch's Fools Crow. While the text of Fools Crow does not begin at the origin of the world, interior episodes reveal that beginning. Raven tells the protagonist of Napi's creation of the world, and Fools Crow's vision of So-at-sa-ki's hide calender reveals the future. Nora Barry sees this protagonist and his counterpart, the culture hero Scarface (who, in traditional oral performances, brought the sun dance to the historical Blackfeet) as mediating figures in Levi-Strauss' terms. Barry focuses on their mediation between cosmic spatial categories (fabulous sky world and ordinary human dimension) through their respective visions. Fools Crow as visionary also mediates between past and future for the nineteenth-century fictional Pikunis. Furthermore, as storyteller whose function is to "preserve the oral tradition" for the future (Barry 4), like the author himself, Fools Crow mediates between the Blackfoot past and the twentieth century.

Such presentations of history, as narratives focused around and through the individual "now," suggest that for these authors the "recovery of the past," in Peter Brooks' phrasing, includes not only specific content (as in the case of the unnamed protagonist of Winter) but also form (as in the circular shape). "The center," which grounds the individual in surrounding geographical, spiritual and 
psychological dimensions as an element of poetic construction intentionally "interrelates" the community's entire social history, mythic and documented, through that individual present.

Among these writers, Momaday most explicitly includes circularity and centering as principles of his poetics in The Ancient Child. In the Epigraph from Borges - "for myth is at the beginning of literature, and also at its end," Momaday identifies the novel itself as a transformation process that takes the form of a circular departure and return - a movement through style with a "beginning" and an "end" that are the same (i.e., "myth"). The narrative accomplishes that transformation as the contemporary artist, Locke Setman, becomes the mythic boy/bear and his cousin/wife Grey, as a storyteller, becomes a powerful medicine woman and medium of transformation. The "Planes," "Lines," "Shapes," and "Shadows" of the novel are framed by opening and closing images that confirm Borges' epigraphic circle [4].

The Prologue recounts the "Kiowa story of Tsoaie," the story of the boy who, in chasing his sisters, becomes a bear and his sisters stars. The Epilogue reiterates the opening images of stars, bear, and disappearing children. In the Epilogue, "Koi-ehm-toya's great-great-grandson," a maker of shields that are "the most powerful medicines," represents the circle that synchronizes distant myth and present history. Koi-ehm-toya dreams: of things that happened before his time. The whole history of the people was played out ... across the plane of his dreaming. And the last of his dreams was that of children moving to a wall of woods. They bobbed and skipped and tumbled away in the distance ... and then he could no longer see them. They had already entered into the trees, into the darkness [4].

By referencing the prologue's images, this final vision closes the circle of the text at the border between the ordinary and the fabulous, the shadowy boundary where the dreams of Grey, the storyteller, and of Koi-ehm-toya, the maker of shields can take on "shapes."

Much like Erdrich's closing of Tracks in its multidimensional relevance to the preceding narrative, the epilogue as metanarration also underscores the circle of the text as dynamic process. "Koi-ehm-toya" is the name of the mythic witness of the original transformation. "Koiehm-toya" is also the Kiowa name of Grey, the witness of the contemporary transformation. The epilogue's dreaming maker of shields, then, is both Set's and Grey's great-great-grandson and their ancestor. This witnessing of transformation across the generations gives cultural and historical, as well as individual, import to Grey's comment, "there is one story . . . and we tell it endlessly because we must; it is the definition of our being" [4]. Momaday's structure, like Silko's in Ceremony [8], argues subtextually that all novel's voices, mythic and literary, manifest an expressive process that is constantly renewable culturally and individually in present space, person, and voice.

All voices are valuable in Momaday's expressive universe, but not all are equidistant from the experiental center of the story. In the search for the center on the "plane" of language, the novel presents two forms of discourse that function beyond the point where ordinary discourse fails. Momaday identifies one of these forms explicitly as "the words of a child, which are at the center of language" [4]; but he implicitly demonstrates the mythic voicing as also close to the silent source of all expression.

\section{Results}

Images that underscore the limitations of conventional literary discourse appear throughout the work. For example, neither "romantic" nor "realistic" tones can reveal Grey's beauty ("on the whole, she was beautiful beyond the telling"). Billy the Kid's story, into which the adolescent Grey creates herself, illustrates similar stylistic limitations. Billy, "a man of few words" [4], speaks only in formal, chivalric tones, and his story is limited to formal heroic modes of life and death. He cannot move beyond Grey's fantasy. Furthermore, the tangible can intrude shockingly on that fantasy as it does when Grey wakes from dreaming of Billy, in a parody of the dime novel romantic interludes to find herself being raped by Dwight Dicks. Neither the historically realistic nor the dime novel romance, Momaday's "multi-language" text argues, can cross the boundary between the imagined and the experienced.

On the other hand, the images of Set, of the Rock Tree Boy, and of the small visitor to the Piegan camp slipping finally into a mythic dimension emphasize the special role of the mythic voice. From one perspective, since the Piegan people lack a language using which they can address or "recognize" their small visitor, the boy remains limited to a "mythic" style and conceptual dimension. But from another point of view this incident suggests possibility, rather than limitation. Like Erdrich's Fleur and Silko's Ts'eh, the Rock-Tree boy and Set can move for Grey from legend into personal history. The indeterminate outlines of mythic figures give them fabulous power as mediums for expressing undefined experience.

\section{Discussion}

One critical way Momaday's characters release the power at the indeterminate boundary between the tangible and the sensed is by naming. Grey and the dying grandmother, in a literal sense, bring Set forth out of the silence; they "create" him by calling his name. Set as "Loki" first enters the text of the novel after the dying grandmother voices his Kiowa names [4]. That naming moment is also the beginning of his personal transformation. The metanarration expressed through Set's father - "this matter of having no name is perhaps the center of the story" - underscores a critical difference between the elusive visitor to the Piegan Camp and the character who centers Momaday's "design." Unlike the small visitor, Set has a name.

Momaday's choice for the title of his autobiography The Names, gives significance to his linkage of naming to "the center of the story." That linkage, like the centering strategies of directional referents, symbolic circles, and movement toward the "Middle place," has ancient 
indigenous parallels. Traditional precedents often underscore an author's self-awareness, and in this particular instance, they foreground Momaday's examination, as an artist, of the roots of perception itself. Barre Toelken, drawing on the work of Gary Witherspoon, observes, "The Navajos believe that language does not merely describe reality; it creates it" [6]. Momaday's essay "Man Made of Words" is often cited as demonstrating the author's similar conception of language itself as experiential mode.

The Navajo are not alone among Native peoples in looking closely at the intersection of language and perceived experience. The origin myth of Acoma implies a parallel exploration. The Acoma primordial twin sisters, whose origin is the dark center place below the Emergence, receive from their "father" baskets that contain animal forms. The storyteller specifies the naming action in this original center as instrumental to genesis of palpable life. The sisters "gave life to all of these animals, giving them names as they came to life". Allen's origin story takes a parallel form: [the sisters] said, "We will name. We will think." . . Thus finished they everything .

Singing, chanting, shaking, crooning, they named everything. Thus made them everything ready for their children (Woman 2) [1].

Overt signification, as through representative personae (e.g., the animal archetypes), then, releases the creative power at "the center." In characterizing Loki/Set as a graphic artist, Momaday makes his protagonist a persona representative of that essential creative impulse.

But no form of discourse, whether that of the artist/protagonist, of his storyteller wife, or of Momaday, the writer, can fully represent this essential generative center within any design. Despite the variety of shapes language can take in Momaday's expressive universe, the opening chapter's essential questioning implicitly enters into the closing: "'Quien es?' / Well, where do you come from? / And where do you go? . . My Cotton Eye Joe?". Like the "fierce dry wind" that is Erdrich's fictional child, Lulu, and like the children bobbing, skipping, and tumbling into the darkness, the silent source of creative expression cannot finally be contained by human voices regardless of style. Even the words of a child and mythic discourse, as Momaday's second novel argues, must be suggestive rather than definitive before that essential generative impulse toward life and art.

References to extraliterary artistic genres are sand painting, opera, and shield making, for example - the novel contains critical moments of nonverbal communication. The small visitor to the Piegan camp, whose language is unknown, exemplifies such moment. Another example appears as Grey listens to the voice at the Grandmother's grave, "not at the level of language but beneath it, in the deep recesses of imagination" [4]. Even at closing the metanarration validates extraliterary expressive modes as approaches to the silent center. Set, like the maker of shields, remains a graphic artist. In the summer prior to his final transformation into the shadow space, he teaches Grey's eight-year-old niece, Nanibah, to paint. A mark of Momaday's self-reflexive artistry is his validation of multiple approaches to the silent center of experience and art.
A parallel validation of the silent grounding of creativity can be found in the prehispanic Nahuati poetry of Mexico. The silence that empowers readers to respond to Rainy Mountain, the silence that empowers the prehispanic Nahuatl poets is identified in The Ancient Child as a center grounding essential to discourse.

The nature of this silent multidimensional center that is process as well as location, Momaday argues, can only be approximated. As he did in House, he privileges "motion" as the trope most appropriate to that approximation. As Set prepares for his wedding, he runs each morning. In that running, he affirms the cosmic design: he enters into the current of the wind, of water running, of shadows extending, of sounds rising up and falling away. His life was in motion; in motion was his life. He ran until running became the best expression of his spirit, until it seemed he could not stop, that if he stopped he would lose his place in the design of creation [4].

Set thus joins the silversided fish "darting and rolling and spinning" on the ocean, "the great gray migrant geese flying under the moon," and the runners against evil in establishing "perspective, proportion, design in the universe" - in motion he "discovers" and "centers" Momaday's dynamic world.

\section{Conclusion}

The multifaceted concept of "the center" the fundamental importance of spatial cagegories in the narratives of contemporary writers working from Native American cultural heritages $[9,10]$. The concepts of circle, of cardinal axes, of cosmos as hogan, as three-tiered system or as pulsating spiral, are geometric constructs. But as devices for structuring these narratives, these geometric forms are consistently figured dynamically. The movement that Yi-Fu Tuan says is the basis for development of space as abstract concept is evident in Momaday's spaces, as abstraction and as concrete image. Momaday centers his spaces through "motion." These centers are "fixed points" in a relative sense only. And throughout these works spatially significant images reference processes - the sunrise that creates each day on the plains, the children who center the social future, the sometimes ambiguous forces of nature associated with the cardinal points. The traditional diction that describes the southwestern cosmic center itself - the Emergence Place - demonstrates that dynamic quality. Such images, like Momaday's "seed" that is "motion forever," set the geographic, social, and conceptual spaces they define within a geometry of organic process.

The authors' shared tendency to embody particular fabulous spatial categories in representative personae underscores the parameters of these fabulous spaces as organic and processive. Thought Woman, the Spider Creatrix in the place below; Set, at the shadowy center of art and then at its equally ambiguous periphery; Ephanie, the "open doorway" between cultures; Ts'eh, the agent of the North/South axis; the airplane man, associate of "The Above Ones"; Fleur, whose powers link her to Lake Machimanito; Hummingbird who, even "dark" and "at 
rest," evokes the visionary potential of intimate spaces such powerful mediating figures extend the dynamic geometry of the center throughout the cosmic design.

This dynamic geometry also underpins the story itself as a "space." Multiple modes of discourse, expressed through multiple narrating voices, make an energetics of the textual space itself. In the metanarration of Erdrich's storyteller, Pauline, the old men turn "the story over. It comes up different every time, and has no ending, no beginning" [7]. As a circle, surrounding the individual present with family and cultural history and with the shifting shapes of our language(s), the story, like the sunrise, is a renewable process - always the same and always new.

\section{References}

1. P. G. Allen, Bringing Home the Fact: Tradition and Continuity in the Imagination. Recovering the Word: Essays on Native American Literature (Berkeley, California UP, 1987)

2. D. Tedlock, The Way to Rainy Mountain. Popol Vuh (NY: Touchstone, 1996)
3. K. Blaeser, Gerald Vizenor: Writing in the Oral Tradition (Norman: U of Oklahoma Pr, 1996)

4. N. S. Momaday, House Made of Dawn (NY: Harper and Row, 1968)

5. H. Jaskoski, (ed). Early Native American Writing: New Critical Essays (London: Cambridge U Pr, 1996)

6. J. Barre Toelken, Dynamics of Folklore (Salt Lake City: Utah State U Pr, 1996)

7. L. Erdrich, Tracks (NY: Harper, 2004)

8. L. M. Silko, Ceremony (New York, Penguin Books Ltd., 1988)

9. P. G. Allen, The Sacred Hoop: A Contemporary Perspective. In C. Glotfelty and H. Fromm (Eds.), The Ecocriticism Reader: Landmarks in Literary Ecology (Athens, University of Georgia Press, 1996)

10. J. Bruchac, Between Earth and Sky: Legends of Native American Sacred Places (NY: Harcourt Brace and Co., 1996) 